\title{
Natural variants of $\alpha$-gliadin peptides within wheat proteins with reduced toxicity in coeliac disease
}

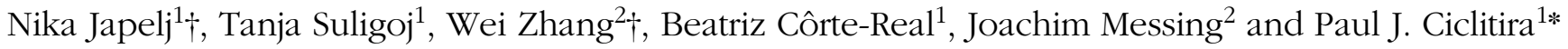 \\ ${ }^{1}$ St Thomas' Hospital, Guy's \& St Thomas' NHS Foundation Trust, London, UK \\ ${ }^{2}$ Waksman Institute of Microbiology, Rutgers University, Piscataway, NJ 08854, USA \\ (Submitted 16 September 2019 - Final revision received 31 January 2020 - Accepted 18 February 2020 - First published online 26 February 2020)
}

\begin{abstract}
The only generally accepted treatment of coeliac disease (CD) is a lifelong gluten-free diet. Wheat gluten proteins include gliadins, low and high molecular weight glutenins. However, we have found significant structural variations within these protein families among different cultivars. To determine which structural motifs might be less toxic than others, we assessed five variants of $\alpha$-gliadin immunodominant CD-toxic peptides synthesised as 16mers in CD T cell stimulation assays with gluten-sensitive T cell lines generated from duodenal biopsies from CD-affected individuals. The peptides harboured the overlapping T cell epitopes DQ 2.5-glia- $\alpha$-2 and naturally occurring variants that differed in certain amino acids (AA). The results revealed that introduction of two selected AA substitutions in $\alpha$-gliadin peptides reduced immunogenicity. A peptide with three AA substitutions involving two glutamic acids (E) and one glutamine residue (G) revealed the peptide was negative in 5:5 samples. We used CD small-intestinal organ culture to assess CD toxicity that revealed two peptides with selected substitution of both glutamic acid (E) and proline (P) residues abrogated evidence of CD toxicity.
\end{abstract}

Key words: Coeliac disease: Gluten-free diet: Gliadin: Low and high molecular weight glutenins: Gluten-sensitive T cells: Duodenal biopsy organ culture

\section{What you need to know}

Background: Coeliac disease (CD) is exacerbated by gluten proteins in wheat and related cereals that have been characterised.

Findings: CD-toxic peptides contain glutamine and proline residues which if singly substituted in CD-toxic peptides decreases or if jointly changed abrogates CD toxicity; certain naturally occurring wheat glutens do not contain CD-toxic motifs.

Implications for patient care: The findings permit the potential generation of (a) a novel cereal that produces flour with the baking and sensorial characteristics of wheat that we hypothesise is non-toxic to subjects with CD and (b) non-GM wheat, using standard breeding techniques that may be $\mathrm{CD}$ safe.

Coeliac disease (CD) is a common T cell inflammatory disorder that affects $1-2 \%$ of individuals worldwide. The management of the condition involves a gluten-free diet (GFD) with avoidance of wheat and related cereals ${ }^{(1)}$. A GFD is restrictive, resulting in reduced quality of life ${ }^{(3,4)}$. The condition is exacerbated by gluten proteins from wheat and homologous proteins from barley, rye and potentially oats. CD manifests in genetically predisposed individuals who have the genes that encode the HLA variants DQ2 or DQ8. Adaptive immune response in these individuals is activated by the interaction between gluten peptides bound on HLA-DQ2/HLA-DQ8 molecules on antigen presenting cells and $\mathrm{T}$ cell receptors on the surface of smallintestinal CD4+ T cells. Fully activated inflammatory response mediated by $\mathrm{T}$ cells leads to tissue damage in the small intestine as an atrophy of the intestinal villi and crypt proliferation. There is evidence that an additional pathway is involved in CD pathogenesis supporting an innate enterocyte as well as an adaptive $\mathrm{T}$ cell response. Initial epithelial damage was observed $1 \mathrm{~h}$ following ingestion of gluten, which is too early for a fully activated $\mathrm{T}$ cell response ${ }^{(4)}$. Moreover, it has been shown that some gluten peptides cause tissue damage without stimulating CD4+ T cells. It is established that the adaptive immune response is through $\mathrm{CD} 4+\mathrm{T}$ cells and an innate immune response mediated by IL-15 co-operates to cause small-intestinal tissue damage ${ }^{(5)}$.

Gluten is principally composed of gliadins, low and high molecular weight glutenins, all three classes of which have been

Abbreviations: AA, amino acids; CD, coeliac disease; E, glutamic acid; ESCH, enterocyte surface-cell height; GFD, gluten-free diet; K, lysine; P, proline; PT, peptic tryptic; S, serine; SI, stimulation index; Q, glutamine.

* Corresponding author: Paul J Ciclitira, email gastropjc@gmail.com

$\dagger$ These authors contributed equally to this work as first authors. 
reported to be CD toxic ${ }^{(4-8)}$. Previous studies suggested that gliadins tend to be more toxic than glutenins and, therefore, have been the subject of many CD toxicity research studies ${ }^{(5)}$. Gliadins can be further divided into $\alpha, \gamma$ and $\omega$ fractions, according to their electrophoretic mobility. Studies have suggested that within gliadins, $\alpha$-gliadins are the most CD toxic ${ }^{(7)}$. Proline (P) and glutamine (G) amino acid (AA) residues are of particular relevance for CD pathogenesis. The $\alpha$-gliadins have high contents of both AA, especially in their N-terminal part ${ }^{(9)}$. We considered the effect of digestion that is known to result in the generation of a 33mer long fragment from the N-terminal part of $\alpha$-gliadins, which related to our choice of peptides for evaluation. Such a fragment includes several CD-toxic epitopes (DQ2.5-glia- $\alpha 2$, DQ2.5-glia- $\alpha 1$ and DQ2-glia- $\alpha 1 \mathrm{~b}$ ), which bind well with HLA-DQ2 and HLA-DQ8 molecules and are recognised by gluten-sensitive T cells ${ }^{(8-10)}$.

As a consequence of nucleotide substitutions of $\alpha$-gliadin genes during the evolution of cereals, naturally existing AA sequence variations of $\alpha$-gliadins have been found within wheat species. Such large-scale analysis of full-length $\alpha$-gliadin complementary DNA (cDNA) became possible because the new sequencing platform enabled each cDNA to be sequenced in the respective entire length ${ }^{(11)}$. This aspect is critical because $\alpha$-gliadins have a repetitive sequence motif preventing the reconstruction of individual cDNA from overlapping sequence information. Taking such an approach, one can ask whether natural variations among wheat species can be used to identify $\alpha$-gliadin genes that encode proteins with reduced content of $\mathrm{T}$ cell epitopes without loss of bread-making qualities. Then, the question remains whether these variants of $\mathrm{T}$ cell stimulatory epitopes have reduced immunogenicity for CD-affected subjects. Given a list of known toxic epitopes to date ${ }^{(9)}$, previous studies have shown that a single AA substitution within a $T$ cell epitope may be able to eliminate the immunogenicity of gluten peptides and it was reported these CD-toxic epitopes are not broken down by inter-luminal digestive enzymes ${ }^{(12-14)}$. Therefore, we investigated the immunogenic potential of $\mathrm{T}$ cell epitopes and their naturally existing variants with $\mathrm{T}$ cell proliferation assays with $\mathrm{CD}$ small-intestinal gluten-sensitive $\mathrm{T}$ cells. Knowing the heterogenic response of cell lines from different patients on the same epitopes, our study was carried out using polyclonal gluten-specific $\mathrm{T}$ cell lines isolated from duodenal biopsies. An in vitro model involving small-intestinal organ culture was used as an additional method to examine CD toxicity of each $\alpha$-gliadin peptide that enabled us to mimic the environment in the human intestine more closely, following generation of peptides, due to digestion by luminal enzymes, including pepsin and trypsin.

In our study, we sought to characterise CD-toxic gluten epitopes and their naturally existing sequence variants. Screening for sequences within gluten proteins that are non-toxic would have significant implications in utilising naturally occurring variants, including the potential to design CD non-toxic wheat proteins, with reduction or absence of $\mathrm{CD}$ toxicity. Furthermore, genes encoding specifically selected CD non-toxic sequences of gluten proteins could be expressed in a gluten-free cereal. This would potentially enable production of flour with the sensorial and baking characteristics of wheat but with a preserved CD non-toxic profile, although the rheological characteristics of the resultant flour would need to be assessed.

\section{Methods}

\section{Synthetic peptides}

Peptides including variations of known epitopes were synthesised as 16 mers with $95 \%$ purity by Selleck Chemicals (www. selleckchem.com). The choice of the peptides from $\alpha$-gliadin followed previously reported CD-toxic epitopes ${ }^{(8-10,12-14,18)}$.

\section{Patients}

Small-intestinal biopsies were taken during follow-up evaluation in subjects with suspected or known CD. Out of fifteen, six were on a normal diet and nine on a GFD (Table 1). In line with the British Society of Gastroenterology Guidelines for the management of Coeliac Disease ${ }^{(15)}$, subjects were diagnosed according to these guidelines. All the subjects ( $n$ 15) read and signed the informed consent form. The study was approved by the St Thomas' Hospital Research Ethics Committee institutional review board, reference numbers 05/Q0207/167. Participating patients were typified as HLA-DQ2 positive and in one case as DQ8 positive. The subjects included eleven females and four males (Table 1 ) with a median age of 41 years and an age range from 27 to 64 years. Biopsies were taken from the second part of the duodenum, a common procedure required for the management of the condition in adults ${ }^{(1)}$.

\section{Preparation of antigens}

Industrial gluten (Vital Wheat Gluten, Roquette UK Ltd) and ovalbumin were peptic tryptic (PT) digested following Frazer's method $^{(16)}$ to serve, respectively, as positive and negative controls. PT digests were further deamidated using a deamidation mix as follows: $100 \mu \mathrm{g} / \mathrm{ml}$ PT-digested gluten or ovalbumin and $2 \mathrm{~mm}$ calcium chloride. The mixtures were incubated at

Table 1. Details of coeliac disease volunteers from whom small-intestinal biopsies were taken for research purposes*

\begin{tabular}{llccc}
\hline Patient & Sex & $\begin{array}{c}\text { Age at time } \\
\text { of biopsy (years) }\end{array}$ & GFD (years) & DQ status \\
\hline Patient A & Female & 41 & 0 & DQ2 \\
Patient B & Female & 40 & 0.33 & DQ2 \\
Patient C & Male & 34 & 0 & DQ2 \\
Patient D & Female & 59 & 0 & DQ2 \\
Patient E & Female & 32 & 11 & DQ2 \\
Patient F & Male & 55 & 0 & DQ2 \\
Patient G & Female & 63 & 13 & DQ2 \\
Patient H & Female & 27 & 1 & DQ2 \\
Patient I & Female & 31 & 0 & DQ2 \\
Patient J & Male & 36 & 1.5 & DQ2 \\
Patient K & Male & 60 & 0.58 & DQ2 \\
Patient L & Female & 49 & 0 & DQ2 \\
Patient M & Female & 28 & 4 & DQ2 \\
Patient N & Female & 64 & 8 & DQ2 \\
Patient O & Female & 57 & 1 & DQ8 \\
\hline
\end{tabular}

GFD, gluten-free diet

* Their sex, age, DQ status and period on a GFD were recorded on the day of the procedure. 
$37^{\circ} \mathrm{C}$ for $4 \mathrm{~h}$. PT and tissue transglutaminase pre-treated gluten were used for restimulation in $\mathrm{T}$ cell studies and as positive control in proliferation assays and organ culture. Ovalbumin was used as a negative control in organ culture assays. In all the proliferation assays employing ovalbumin, this control protein always resulted in a negative stimulation index $(\mathrm{SI}<2)$. Therefore, medium only subsequently served as a negative control.

\section{Establishment of small-intestinal T cell lines}

The methods were undertaken as previously described ${ }^{(7,14)}$. Small-intestinal biopsies from CD-affected subjects were challenged overnight in an organ culture chamber in contact with $5 \mathrm{mg} / \mathrm{ml} \mathrm{PT-digested} \mathrm{gluten} \mathrm{solution.} \mathrm{Lymphocytes} \mathrm{were} \mathrm{iso-}$ lated by mechanical disruption of biopsies the next day and passed through a $70 \mu \mathrm{m}$ cell filter (Falcon; Becton Dickson Ltd). T cells were cultured in the Roswell Park Memorial Institute (RPMI) 1640 tissue culture medium supplemented with $10 \%$ heat inactivated autologous serum, plasmocin $2.5 \mu \mathrm{g} / \mathrm{ml}$; (Invivigen Ltd, Cayla), amphotericin B $(0.25 \mathrm{mg} / \mathrm{ml}$; PAA Cell Culture Company) and Hepes buffer. The medium was refreshed every 2-3 d, and IL-2 (17903, Sigma) was added as a growth factor. Every seventh day, cells were restimulated with autologous irradiated peripheral blood mononuclear cells (22 Grey) that had been previously incubated with PT-digested and tissue transglutaminase-treated gluten.

\section{$T$ cell proliferation assays}

The $\mathrm{T}$ cells used were obtained following 1-4 weeks in culture prior to testing in $\mathrm{T}$ cell proliferation assays, depending on the growth of the cells. Complex antigen (gluten) was incubated with antigen presenting cells $\left(5 \times 10^{6}\right)$; plates were incubated for $48 \mathrm{~h}$. Tritiated thymidine was added (NET355, Perkin Elmer) for $18 \mathrm{~h}$ prior to harvesting with a Tomtec Cell Harvester. The level of thymidine incorporation in the T cell DNA was measured using a Wallac 1450 Microbeta Plus liquid scintillation counter. SI were calculated following the equation:

$$
\begin{aligned}
\mathrm{SI}= & \text { mean counts per } \min \text { for } \mathrm{T} \text { cells } \\
& + \text { antigen } / \text { mean counts per min for } \mathrm{T} \text { cells }+ \text { APC. }
\end{aligned}
$$

An SI of 2 or more was considered positive.

\section{Duodenal biopsy organ culture}

Paired duodenal biopsies from CD patients were placed in separate organ culture dishes containing either $1 \mathrm{mg} / \mathrm{ml}$ of PT-digested gluten as a positive control ${ }^{(7,17)}$ or $200 \mu \mathrm{g} / \mathrm{ml}$ of individual peptide (peptides 3, 5, 6 and 9). Following overnight incubation, the biopsies were fixed in $10 \%$ formaldehyde solution and after at least $48 \mathrm{~h}$ embedded in paraffin (Thermo Shandon Histocentre 3 Embedding Station). Tissue blocks were cut to a $5 \mu \mathrm{m}$ thickness and stained with haematoxylin-eosin. Sections were microscopically examined, selecting at least three villi in order to measure the enterocyte surface-cell height (ESCH), one third of the way down the villi, ten continuous enterocytes were measured on each villus, giving a total of thirty $\mathrm{ESCH}$ (haematoxylin-eosin) measurements for each section. Where villi were not able to be identified but the enterocyte layer was clear, measurements were taken from the middle of the section. Means of ESCH for the sample groups were compared. An ANOVA statistical analysis was used to compare mean ESCH between sample groups.

\section{Results}

\section{Selection of sequence motifs for epitope analysis}

A common path to identify epitopes has been the use of peptide arrays ${ }^{(19)}$. Although one can argue that in such cases peptides do not represent natural epitopes because their sequences might be hidden due to the three-dimensional structure of proteins and not immunogenic in the native protein, this does not apply to gluten proteins because they are digested and hydrolysed into many small peptide fragments, when they reach the small intestine. Therefore, one can use synthetic peptides to simulate gluten epitopes that affect CD patients. Previously, $\alpha$-gliadins from ten diverse wheat cultivars had been sequenced and assembled using the PacBio system ${ }^{(11)}$. These assembled sequences were aligned to identify variations in sequence motifs (Fig. 1). Peptides including variations of known epitopes were synthesised as 16 mers with $95 \%$ purity as described under Methods. In this study, we present the results of toxicity testing of $\alpha$-gliadin peptides marked as peptides 1, 3, 5, 6 and 9 for their simplicity of labelling in the text and tables. Peptide 1 harbours CD-toxic gluten epitopes (DQ2.5-glia- $\alpha$-1a or DQ2.5-glia- $\alpha 2$ ); peptide 3 is the deamidated counterpart at positions $\mathrm{p} 65$ and p72; peptides 5 and 6 are deamidated naturally existing variants of peptide 1 ; peptide 9 does not naturally exist, but was designed to have glutamine at p63, p65 and p70 mutated to lysine (Table 2). Peptides $1,3,5,6$ and 9 were tested for recognition by eleven polyclonal $\mathrm{T}$ cell lines, specific for gluten (Table 2). Proliferation assays for each antigen were performed in triplicate. $\mathrm{CV}$ of triplicates were calculated, and CV 0.2 or less was considered as acceptable variability. Results are presented as SI with corresponding arithmetic mean and one standard deviation (Table 3). The results for Patient O, who was HLA-DQ8 in Table 4, were no different from the others who had the HLA-DQ2 allele.

\section{Deamidation of dominant gluten epitopes in $\alpha$-gliadins}

Peptide 1 (QLQPFPQPQLPYPQPQ) is an immunodominant peptide harbouring overlapping $\mathrm{T}$ cell epitopes; DQ2.5-glia- $\alpha 1 \mathrm{a}$, DQ2.5-glia- $\alpha 2$ and part of DQ2.5-glia- $\alpha 1 \mathrm{~b}$ (from a nomenclature of CD-toxic epitopes) $)^{(9)}$. To confirm the importance of deamidation at position p 65 and p 72 of $\alpha$-gliadin, a deamidated counterpart (peptide 3) was tested in ten gluten-specific cell lines with proliferation assays determined. A table of responses for both peptides is shown in Table 3 with the SI.

Even though peptide 1 and its deaminated counterpart (peptide 3) were evaluated in previous studies as immunodominant peptides, they had not been tested positive (SI $>2$ ) in all the tested T cell lines. Approximately half of gluten-specific cell lines (7/15) recognise peptide 1 or peptide 3 (Fig. 2).

SI varied from 0.7 to 14.76 . This confirms the different sensitivity of $\mathrm{T}$ cells obtained from $\mathrm{CD}$-affected subjects to specific 
Sample5_alpha_contig11

Sample10_alphā_contig10

Sample2_alpha_contig13

Sample4_alpha_contig1

Sample4_alpha-contig4 $(7,31)$

Sample3_alpha_contig32

Sample2_alpha_contig13-2

Sample10_alphā_contig8

Sample10_alpha_contig13

Sample7_alpha_contig9

Sample2_alpha_contig9

Sample9_alpha_contig3

Sample5_alpha_contig5

Sample7_alpha_contig7

Sample10̄alphā_contig18

Sample7_alpha_contig10

Sample8_alpha_contig2

Sample3_alpha_contig18

Sample8_alpha_contig1

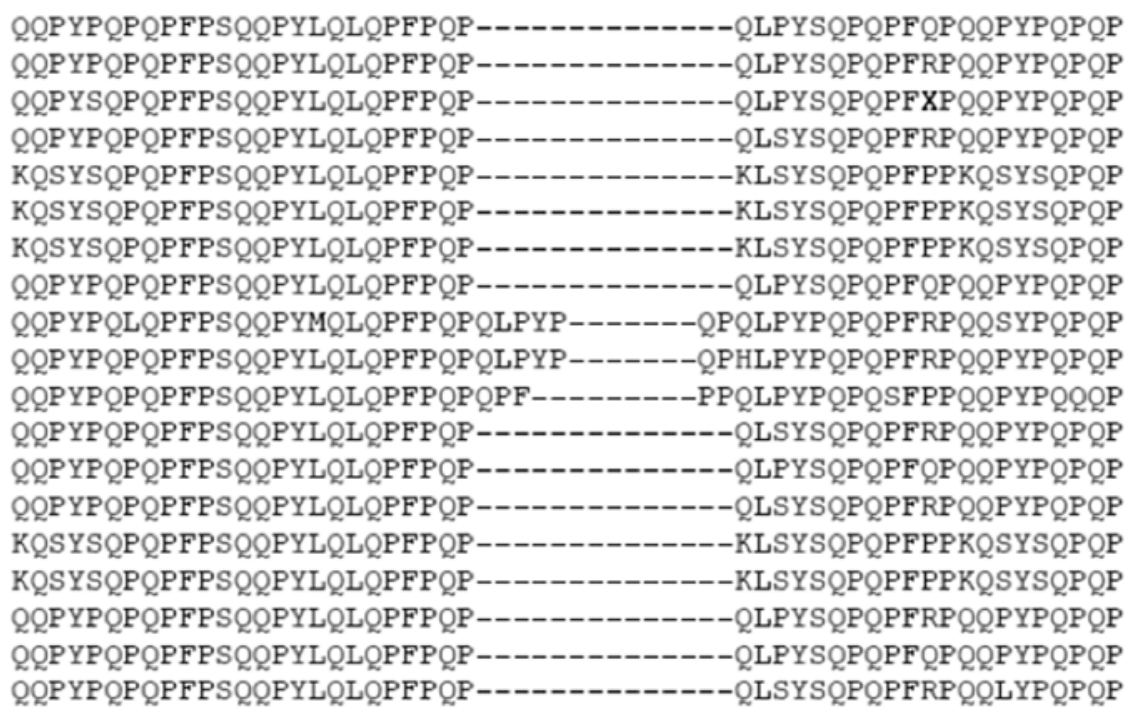

Fig. 1. Snapshot alignment of DQ2.5-glia- $\alpha 1$ and DQ2.5-glia- $\alpha 2$ region in ten wheat cultivars used in a previous study ${ }^{(11)}$.

Table 2. Amino acid sequences for $\alpha$-gliadin peptides and substituted variants used in the study

Peptide Sequence Substitutions

\begin{tabular}{|c|c|c|c|c|c|c|c|c|c|c|c|c|c|c|c|c|c|}
\hline Peptide 1 & $\begin{array}{c}57 \\
\mathrm{Q}\end{array}$ & $\begin{array}{c}58 \\
\mathrm{~L}\end{array}$ & $\begin{array}{c}59 \\
Q\end{array}$ & $\begin{array}{c}60 \\
P\end{array}$ & $\begin{array}{c}61 \\
\mathrm{~F}\end{array}$ & $\begin{array}{c}62 \\
P\end{array}$ & $\begin{array}{c}63 \\
Q\end{array}$ & $\begin{array}{c}64 \\
P\end{array}$ & $\begin{array}{c}65 \\
Q\end{array}$ & $\begin{array}{c}66 \\
\mathrm{~L}\end{array}$ & $\begin{array}{c}67 \\
P\end{array}$ & $\begin{array}{l}68 \\
Y\end{array}$ & $\begin{array}{c}69 \\
P\end{array}$ & $\begin{array}{c}70 \\
Q\end{array}$ & $\begin{array}{c}71 \\
P\end{array}$ & $\begin{array}{c}72 \\
\mathrm{Q}\end{array}$ & \\
\hline Peptide 3 & $\mathrm{Q}$ & L & $\hat{Q}$ & $\mathrm{P}$ & $\mathrm{F}$ & $\mathrm{P}$ & $\bar{Q}$ & $\mathrm{P}$ & $\mathrm{E}^{*}$ & $\mathrm{~L}$ & $\mathrm{P}$ & $\mathrm{Y}$ & $\mathrm{P}$ & $\mathrm{Q}$ & $\mathrm{P}$ & $\mathrm{E}^{*}$ & Deamidated \\
\hline Peptide 5 & Q & L & Q & $\mathrm{P}$ & $\mathrm{F}$ & $\mathrm{P}$ & Q & $\mathrm{P}$ & $\mathrm{E}$ & L & $\mathrm{S}^{\star}$ & $\mathrm{Y}$ & $\mathrm{P}$ & Q & $\mathrm{P}$ & $E^{*}$ & S67 \\
\hline Peptide 6 & Q & $\mathrm{L}$ & Q & $\mathrm{P}$ & $\mathrm{F}$ & $\mathrm{P}$ & Q & $\mathrm{P}$ & $\mathrm{K}^{*}$ & L & $\mathrm{S}^{*}$ & $\mathrm{Y}$ & $\mathrm{P}$ & Q & $\mathrm{P}$ & $E^{\star}$ & K65, S67 \\
\hline Peptide 9 & Q & L & Q & $\mathrm{P}$ & $\mathrm{F}$ & $\mathrm{P}$ & $\mathrm{K}^{\star}$ & $\mathrm{P}$ & $\mathrm{K}^{*}$ & $\mathrm{~L}$ & $\mathrm{P}$ & $\mathrm{Y}$ & $P$ & $\mathrm{~K}^{\star}$ & $\mathrm{P}$ & $E^{\star}$ & K63, K65, K70 \\
\hline Epitope DQ2.5-glia- $\alpha$-1a positions & & & & $\mathrm{p} 1^{*}$ & $\mathrm{p} 2{ }^{*}$ & $\mathrm{p3}^{*}$ & $\mathrm{p} 4^{*}$ & $\mathrm{p} 5^{\star}$ & $\mathrm{p} 6^{*}$ & $\mathrm{p} 7^{*}$ & p8* & p9* & & & & & \\
\hline Epitope DQ1.5-glia- $\alpha 2$ positions & & & & & & $\mathrm{p} 1^{*}$ & p2* & $\mathrm{p3}^{*}$ & $\mathrm{p} 4^{*}$ & $\mathrm{p} 5^{*}$ & $\mathrm{p} 6^{*}$ & $\mathrm{p} 7^{\star}$ & $p 8^{*}$ & p9* & & & \\
\hline
\end{tabular}

${ }^{*}$ Amino acids within the immunodominant p57-p71 peptide are present and the position of their binding into HLA-DQ2 groove (p1, p2 ...).

epitopes. Notably, indices increased when peptide 1 had been deaminated. In the case of four T cell lines (patients B, E and G), the SI for peptide 3 were high and well above the cut-off for positivity $(\mathrm{SI}>2)$.

\section{Amino acid substitutions within T cell epitope in $\alpha$-gliadins}

The results involving peptides 5, 6 and 9 with AA incorporating substitutions in the T cell epitope were compared with those involving the immunodominant peptide 3. We wondered if the $\mathrm{T}$ cell response with these substitutions would be abrogated (Fig. 3). To address the question, in each peptide, higher numbers of substitutions were introduced. In peptide 5 (QLQPFPQPELSYPQPE), proline (P) at position 67 of $\alpha$-gliadin was substituted with serine (S). This peptide triggered a positive response of $\mathrm{T}$ cells in two out of six patients. This was in contrast with the deamidated immunodominant peptide (peptide 3-QLQPFPQPELPYPQPE), with which the immune response was down-regulated, indicating the importance of proline at p67 in triggering the coeliac reaction in some patients. However, this peptide failed to be completely non-immunogenic for all the coeliac patient's gluten-sensitive T cells that were assessed.
Peptide 6 (QLQPFPQPKLSYPQPE) compared with peptide 5 has blocked p65 glutamine from deamidation: glutamic acid (E) at position 65 was substituted with lysine $(\mathrm{K})$ and proline $(\mathrm{P})$ at position 67 with serine (S). Importantly, the response of glutenspecific $\mathrm{T}$ cells was completely abrogated in all the tested cell lines - none of the eight cell lines yielded a positive result. The result points to the importance of p 65 deamidated glutamic acid in triggering the coeliac $\mathrm{T}$ cell response.

Finally, peptide 9 (QLQPFPKPKLPYPKPQ) had mutated deamidation point glutamine at both p65 and p70 (Q-K) and Q-K mutation at p63. Peptide 9 was tested with five polyclonal CD gluten-sensitive $\mathrm{T}$ cell lines. The SI for this peptide was negative $(\mathrm{SI}<2)$ in five out of five samples $(100 \%)$.

The same peptides tested that had been in T cell proliferation assays were assessed in small-intestinal organ culture as the next step to examine their CD toxicity. Mean ESCH were measured as a marker of the CD toxicity of proteins/peptides. Table 4 shows the combined $\mathrm{ESCH}$ for each patient (L, M, N and O) under experimental conditions. Measurements of mean ESCH following overnight incubation of small-intestinal biopsies with medium only/ovalbumin were compared with measurements of 
Table 3. Results of stimulation indices (SI) of eleven proliferation assays; eleven gluten-sensitive T cell lines were tested with medium only, peptic tryptic-digested gluten and peptides 1, 3, 5, 6 and 9 (Mean values and standard deviations)

\begin{tabular}{|c|c|c|c|c|c|c|c|}
\hline Sample & Medium only & Gluten & Peptide 1 & Peptide 3 & Peptide 5 & Peptide 6 & Peptide 9 \\
\hline Patient A & $1.00^{*}$ & $8 \cdot 88^{*}$ & $2 \cdot 36^{*}$ & $1.90^{*}$ & $1 \cdot 85^{\star}$ & $1.44^{*}$ & $1.67^{*}$ \\
\hline Mean & 435 & 3868 & 1028 & 826 & 808 & 627 & 729 \\
\hline Patient B & $1.00^{*}$ & $6 \cdot 17^{*}$ & $2 \cdot 82^{*}$ & $14 \cdot 76^{*}$ & $2 \cdot 61^{*}$ & $0.83^{*}$ & $1.04^{*}$ \\
\hline Mean & 1594 & 9836 & 4492 & 23533 & 4168 & 1326 & 1663 \\
\hline SD & $176 \cdot 8$ & $1573 \cdot 1$ & 338.0 & $144 \cdot 6$ & $117 \cdot 6$ & $263 \cdot 7$ & $258 \cdot 1$ \\
\hline Patient C & $1.00^{*}$ & $3.63^{*}$ & & $1.96^{*}$ & & & $1 \cdot 29^{*}$ \\
\hline Mean & 133 & 484 & & 261 & & & 172 \\
\hline SD & 19.9 & $63 \cdot 3$ & & $54 \cdot 6$ & & & $30 \cdot 8$ \\
\hline Patient D & $1.00^{*}$ & $2.41^{*}$ & $1.63^{*}$ & $1.55^{\star}$ & $1 \cdot 24^{*}$ & & \\
\hline Mean & 235 & 566 & 383 & 364 & 292 & & \\
\hline SD & 23.7 & $96 \cdot 1$ & $65 \cdot 0$ & $49 \cdot 5$ & $29 \cdot 0$ & & \\
\hline Patient E & $1.00^{*}$ & $4 \cdot 17^{*}$ & $3.45^{\star}$ & $6 \cdot 58^{*}$ & $8.54^{*}$ & $1 \cdot 16^{*}$ & \\
\hline Mean & 80 & 331 & 274 & 523 & 679 & 92 & \\
\hline SD & $16 \cdot 1$ & $20 \cdot 7$ & $36 \cdot 7$ & $154 \cdot 1$ & $36 \cdot 6$ & $22 \cdot 6$ & \\
\hline Mean & 629 & 4660 & & & 1026 & & \\
\hline SD & 0 & $191 \cdot 6$ & & & 78.5 & & \\
\hline Patient G & $1.00^{*}$ & $5 \cdot 58^{*}$ & & $5 \cdot 26^{*}$ & & $0.8^{*}$ & $1 \cdot 16^{*}$ \\
\hline Mean & 535 & 2989 & & 2816 & & 431 & 623 \\
\hline SD & $66 \cdot 8$ & $285 \cdot 8$ & & $65 \cdot 8$ & & $58 \cdot 0$ & 84.5 \\
\hline Patient H & $1.00^{*}$ & $53.94^{*}$ & & $0.70^{*}$ & & $0.68^{\star}$ & \\
\hline Mean & 238 & 15248 & & 196 & & 193 & \\
\hline SD & 23.5 & $1536 \cdot 0$ & & $30 \cdot 1$ & & $34 \cdot 8$ & \\
\hline Patient I & $1.00^{*}$ & $3.65^{\star}$ & $1 \cdot 33^{\star}$ & $2.57^{*}$ & $0.91^{*}$ & $0.9^{*}$ & $0.82^{*}$ \\
\hline Mean & 367 & 1340 & 487 & 944 & 335 & 330 & 301 \\
\hline SD & $45 \cdot 2$ & 194.9 & 31.2 & 66.5 & $21 \cdot 7$ & $61 \cdot 7$ & 37 \\
\hline Patient J & $1 \cdot 00^{*}$ & $13^{*}$ & & $1.99^{*}$ & & $1 \cdot 23^{\star}$ & \\
\hline Mean & 52 & 676 & & 104 & & 64 & \\
\hline SD & 0 & $121 \cdot 2$ & & $14 \cdot 8$ & & $5 \cdot 2$ & \\
\hline Patient K & $1.00^{*}$ & $3.47^{\star}$ & & $1.53^{\star}$ & & $1 \cdot 34^{*}$ & \\
\hline Mean & 99 & 344 & & 152 & & 133 & \\
\hline SD & 8.5 & 63.7 & & 3.5 & & $14 \cdot 8$ & \\
\hline
\end{tabular}

${ }^{\star}$ SI for individual antigens, with the corresponding arithmetic means and standard deviations. Note that SI greater than 2 were considered as positive.

Table 4. Comparison of mean enterocyte surface-cell height $(\mathrm{ESCH})(\mu \mathrm{m})$ in coeliac disease patients; paired biopsies were left overnight in the organ culture system under seven conditions: medium only, ovalbumin, peptic tryptic-digested gluten, peptides $3,5,6$ and $9^{*}$

\begin{tabular}{lccccccccccccc}
\hline Sample & Medium & \multicolumn{2}{c}{ Ovalbumin } & \multicolumn{2}{c}{ Gluten } & \multicolumn{2}{c}{ Peptide 3 } & \multicolumn{2}{c}{ Peptide 5 } & \multicolumn{2}{c}{ Peptide 6 } & Peptide 9 \\
\hline Patient L & 27.57 & 28.16 & NS & 13.23 & $P \leq 0.05$ & 15.70 & $P \leq 0.05$ & 12.73 & $P \leq 0.05$ & 25.97 & NS & 25.26 & NS \\
Patient M & 24.99 & 25.87 & NS & 15.34 & $P \leq 0.05$ & 21.50 & $P \leq 0.05$ & 24.53 & NS & 26.14 & NS & 27.86 & NS \\
Patient N & 27.86 & 25.98 & NS & 21.64 & $P \leq 0.05$ & 20.92 & $P \leq 0.05$ & 17.68 & $P \leq 0.05$ & 29.81 & NS & N \\
Patient O & & 28.88 & & 19.82 & $P \leq 0.05$ & 23.65 & $P \leq 0.05$ & 26.03 & NS & 31.21 & NS & 27.69 & NS \\
\hline
\end{tabular}

${ }^{*} P$ values show if the difference between $\mathrm{ESCH}$ is statistically significant when compared with medium.

mean ESCH after incubation of biopsies with PT-digested gluten with different peptides for each patient (Fig. 4).

In all tested samples, mean ESCH for biopsies cultured with digested gluten were significantly reduced in comparison with medium or ovalbumin. In specimens from patient $\mathrm{N}$, mean ESCH from biopsies cultured with ovalbumin was significantly lower than biopsies cultured with medium alone. However, mean ESCH in this sample for ovalbumin was still significantly higher compared with digested gluten $(P=0 \cdot 001)$, peptide 3 $(P<0.0001)$ and peptide $5(P<0.0001)$. In all other samples, mean ESCH between medium alone and ovalbumin did not reach statistical significance.
In all biopsies cultured with peptide 3, a reduction in $\mathrm{ESCH}$ was noted, indicating peptide 3 indeed triggers coeliac reaction in organ culture. There was a trend towards reduced mean ESCH when incubated with peptide 5 in comparison with medium alone and ovalbumin. Nevertheless, when tested on biopsies from patient $\mathrm{O}$, no significant reduction of ESCH was observed. There was no difference in the result from the subject who was HLA-DQ8 compared with HLA-DQ2. This is in accordance with $\mathrm{T}$ cells results that peptide 5 only reduces coeliac response in some but not all patients.

However, when CD tissue incubated with the organ culture medium only was compared with the tissue incubated with 


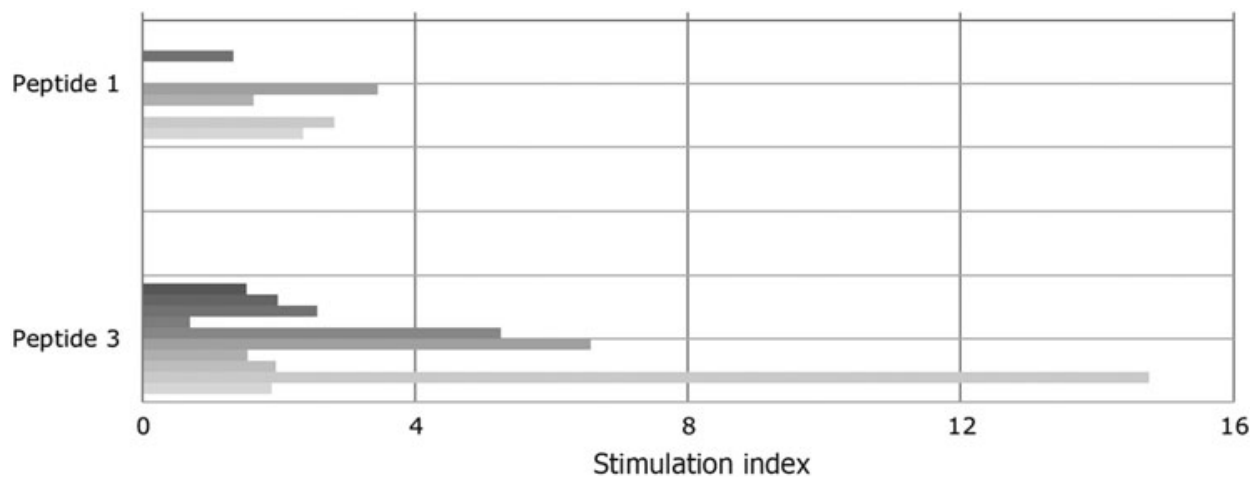

Fig. 2. Proliferative response of T cell lines to immunodominant peptide 1 (epitope DQ2.5-glia- $\alpha 1$ a positions and DQ2.5-glia- $\alpha 2$ ) and to peptide 3, the deamidated counterpart. Tissue transglutaminase increased the stimulatory capacity. The patients are vertically sequentially presented: peptide 1: patients (i) I, (ii) E, (iii) D, (iv) B and (v) A; peptide 3: patients (i) K, (ii) J, (iii) C, (iv) H, (v) G, (vi) E, (vii) D, (viii) J, (ix) B and (x) A.

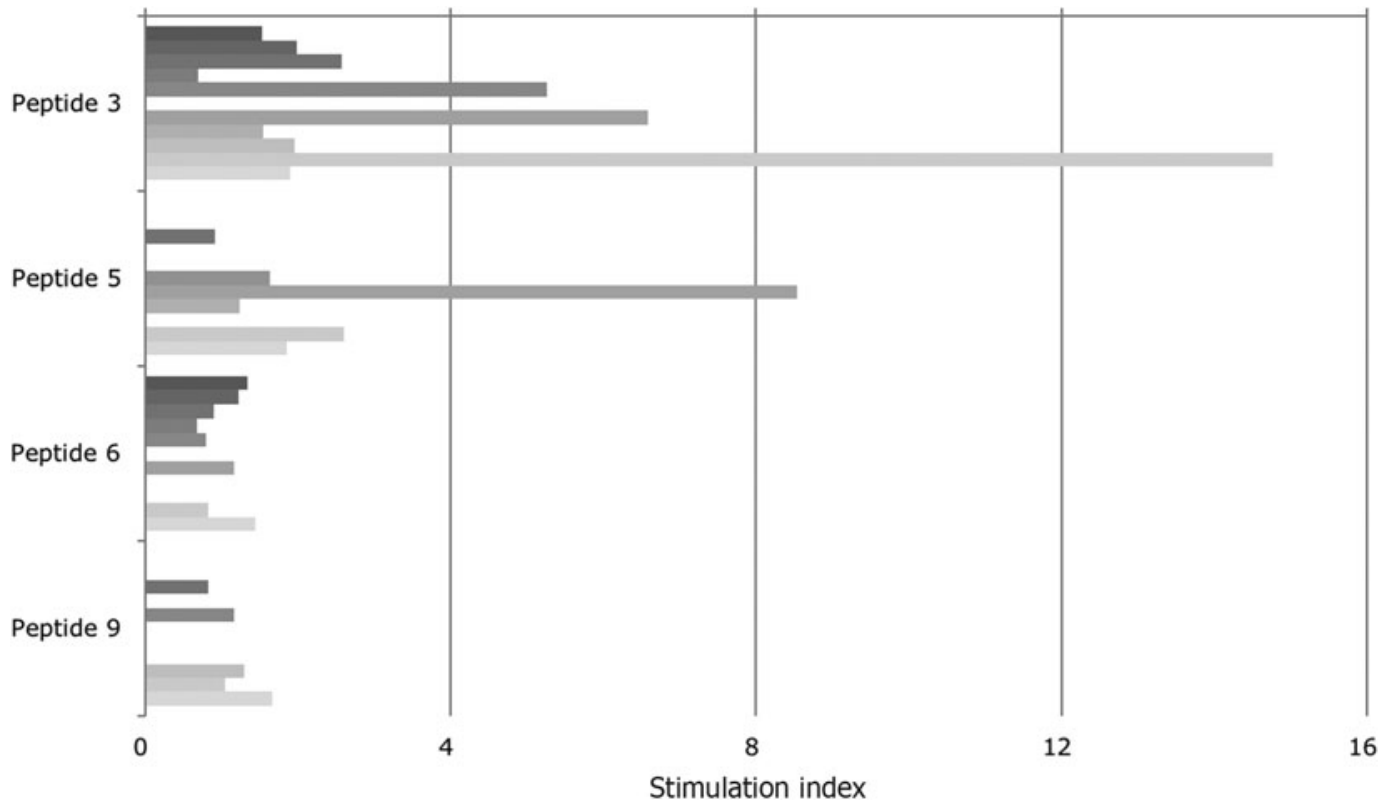

Fig. 3. Proliferative response of T cell lines to different $\alpha$-gliadin peptides: peptide 3 , peptide 5 , peptide 6 and peptide 9 . With every further peptide, one amino acid substitution is introduced. With two amino acid substitutions, $T$ cell response is completely abrogated. The patients are vertically sequentially presented. Peptide 3 : patients (i) K, (ii) J, (iii) I, (iv) H, (v) G, (vi) E, (vii) D, (viii) C, (ix) B and (x) A; peptide 5: patients (i) I, (ii) F, (iii) E, (iv) E, (v) B and (vi) A; peptide 6: patients (i) K, (ii) J, (iii) I, (iv) $H$, (v) $G$ (vi) $E$ (vii) $B$ and (viii) $A$; peptide 9: patients (i) I, (ii) $G$, (iii) $C$, (iv) $B$ and (v) $A$.

peptide 6, there was no statistically significant difference $(P<0.005)$. Likewise, there was no statistically significant difference observed when cultured with peptide $9(P<0 \cdot 05)$ (Table 4). The organ culture results point to the conclusion that deamidated glutamic acid (E) is crucial in triggering coeliac immune response, consistent with previous studies ${ }^{(18)}$.

\section{Discussion}

$\mathrm{CD}$ is a lifelong condition that affects $1-2 \%$ of subjects worldwide. The only generally accepted treatment is a strict lifelong GFD, with avoidance of wheat, rye and barley. This is restrictive with resultant decreased quality of life $\mathrm{e}^{(2,3)}$. Compliance to the GFD is challenging in both adults and children ${ }^{(2)}$. All three classes of wheat gluten of wheat proteins, gliadins, low molecular weight glutenins and high molecular weight glutenins exacerbate CD. The pathogenesis involves apparent adaptive T cell and innate enterocyte gluten-induced damage to the smallintestinal mucosa.

There is a great expectation for alternative therapies among patients and their families ${ }^{(20-23)}$ with the suggestion that wheat deficient in gliadin may provide a promising tool for the treatment of $\mathrm{CD}^{(24)}$.

We assessed five variants of $\alpha$-gliadin immunodominant CD-toxic peptides synthesised as 16mers in CD T cell stimulation assays involving polyclonal gluten-sensitive $\mathrm{T}$ cells generated from duodenal biopsies from $\mathrm{CD}$-affected individuals. The results revealed the mutation of proline $(\mathrm{P})$ to serine $(\mathrm{S})$ of 


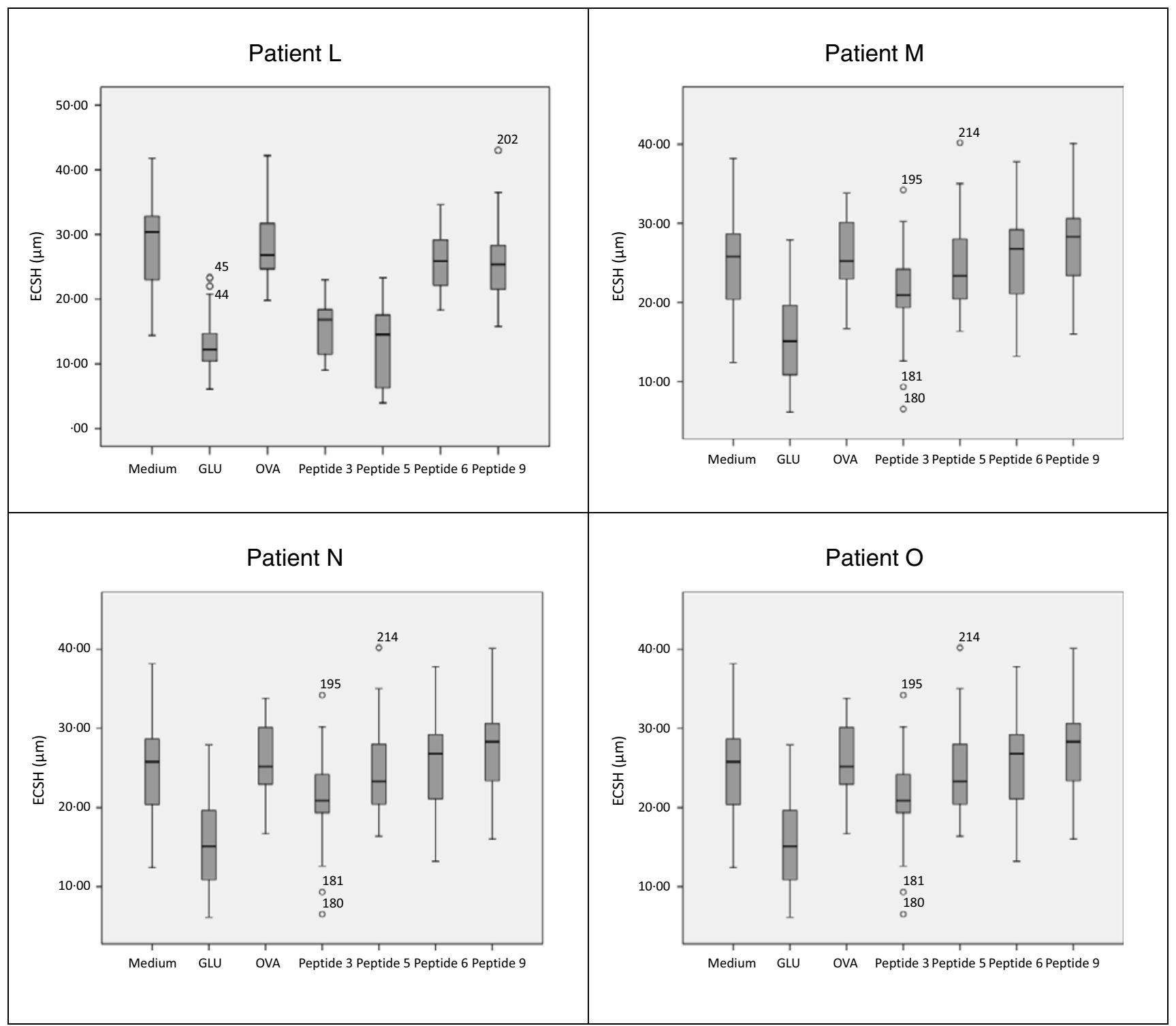

Fig. 4. Results of overnight incubation of paired biopsies with medium only, peptic tryptic (PT)-digested gluten (GLU), PT-digested ovalbumin (OVA) and peptides $3,5,6$ and 9. Figures show median enterocyte surface-cell height (ESCH), first and third quartiles, including minimum and maximum values for each patient.

p67 in $\alpha$-gliadin peptides reduced immunogenicity and further blocking glutamine at $\mathrm{p} 65$ by mutation to lysine completely abrogated immunogenicity, suggesting that such peptides would have reduced CD toxicity. We subsequently used small-intestinal biopsy organ culture to assess CD toxicity that revealed two peptides with selected substitution of both glutamic acid (E) and proline $(\mathrm{P})$ resides abrogated evidence of $\mathrm{CD}$ toxicity. Our study suggests the AA deamidated glutamic acid at p65 and proline at p67 are the most important residues in CD toxicity.

In this pilot study, we tested an experimental platform, with which we can systematically investigate variations of gluten molecules with reduced toxicity for CD patients. A critical aspect of this platform is that it provides a screen before proceeding with in vivo challenge in volunteers, the results of which would have significant implications for patient care. Moreover, it allows us to separate CD toxicity from use of gluten for baking purposes. Indeed, review of our prolamin sequencing data ${ }^{(11)}$ suggests there are naturally occurring wheat prolamins that do not contain CD-toxic motifs pertaining to the peptides tested. We propose this could potentially serve as the basis for developing novel treatment for CD. This would involve gluten proteins including gliadins and glutenins that retain the baking qualities of wheat, but which do not exacerbate CD, including $\alpha$-, $\gamma$-and $\omega$-gliadins, low and high molecular weight glutenins, following which the rheology and sensorial characteristics of the resultant flour would need to be assessed.

\section{Acknowledgements}

The co-authors wish to thank Ms Janet Schulz, for typing up the manuscript

N. J., T. S. and B. C.-R. were supported by The Clinical Research Trust; W. Z. and J. M. were supported by the Selman 
A. Waksman Chair in Molecular Genetics of Rutgers University, NJ, USA, and P. J. C. was supported by Guys and St Thomas NHS Foundation Trust, London, UK.

N. J. with T. S. and B. C.-R. undertook the CD toxicity studies with gluten-sensitive $T$ cells and CD duodenal biopsy organ culture. W. Z. designed and generated the gluten peptides; J. M. supervised W. Z. and was instrumental in design of the study. P. J. C. was jointly instrumental in design of the study and undertook the clinical aspects of the study including taking duodenal biopsies and peripheral blood for purification of antigen presenting cells to generate gluten-sensitive T cells and to undertake CD duodenal biopsy organ culture. He also co-supervised the overall project with J. M. and was instrumental in drafting the manuscript with input from all the co-authors.

The authors declare that the views expressed in the submitted manuscript are their own and not the position of the institution or funders.

\section{References}

1. Ciclitira PJ (2019) Management of celiac disease in adults. UpToDate, August 2019. https://www.uptodate.com/ contents/management-of-celiac-disease-in-adults

2. Nachman F, Mauriño F, Vazquez H, et al. (2009) Quality of life in celiac disease patients: prospective analysis on the importance of clinical severity at diagnosis and the impact of treatment. Dig Liver Dis 41, 15-25.

3. Deepak C, Berry N \& Kochlor B (2018) Quality of life in celiac disease and the effect of gluten-free diet.JGH Open 2, 124-128.

4. Ciclitira PJ, Evans DJ, Fagg NL, et al. (1984) Clinical testing of gliadin fractions in coeliac patients. Clin Sci (Lond) 66, 357-364.

5. Korneychuk N, Ramiro-Puig E \& Ettersperger J, et al. (2014) Interleukin 15 and CD4(+) T cells cooperate to promote small intestinal enteropathy in response to dietary antigen. Gastroenterology 146, 1017-1027.

6. Vader W, Kody Y, van Vailen P, et al. (2002) The gluten response of children with coeliac is directed towards multiple gliadin and glutenin peptides. Gastroenterology 112, 1729-1737.

7. Dewar DH, Amato M, Ellis HJ, et al. (2006) The toxicity of high molecular weight glutenin subunits of wheat to patients with coeliac disease. Eur J Gastroenterol Hepatol 18, 483-491.

8. Molberg O, Solheim Flaete N, Jensen T, et al. (2003) Intestinal T-cell responses to high-molecular-weight glutenins in coeliac disease. Gastroenterology 125, 337-344.
9. Sollid LM, Qiao SW, Anderson RP, et al. (2012) Nomenclature and listing of coeliac disease relevant gluten T-cell epitopes restricted by HLA-DQ molecules. Immunogenetics 64, 455-460.

10. Ellis HJ, Pollock EL, Engel W, et al. (2003) Investigation of the putative immunodominant $\mathrm{T}$ cell epitopes in coeliac disease. Gut 52, 212-217.

11. Zhang W, Ciclitira PJ \& Messing J (2014) PacBio sequencing of gene families - a case study with wheat gluten genes. Gene $\mathbf{5 3 3}, 541-546$

12. Mitea C, Salentijn EM, van Veelen P, et al. (2010) A universal approach to eliminate antigenic properties of alpha-gliadin peptides in coeliac disease. PLOS ONE 5, e15637.

13. Anderson RP, van Heel DA, Tye-Din JA, et al. (2006) Antagonists and non-toxic variants of the dominant wheat gliadin T cell epitope in coeliac disease. Gut 55, 485-491.

14. Molberg O, Uhlen AK, Jensen T, et al. (2005) Mapping of gluten T-cell epitopes in the bread wheat ancestors: implications for coeliac disease. Gastroenterology 128, 393-401.

15. Ludvigsson JF, Bai JC, Biagi F, et al. (2014) Diagnosis and management of adult coeliac disease: guidelines from the British Society of Gastroenterology. Gut 63, 1210-1228.

16. Frazer AC, Fletcher RF, Ross CA, et al. (1959) Gluten-induced enteropathy: the effect of partially digested gluten. Lancet ii, 252-255.

17. Zevallos VF, Ellis HJ, Ciclitira PJ, et al. (2012) Variable activation of immune response by quinoa (chenopodium quinoa wild.) prolamins in celiac disease. Am J Clin Nutr 26, 357-344.

18. Molberg O, McAdam S, Lundin KE, et al. (2001) T cells from coeliac disease lesions recognize gliadin epitopes deamidated in situ by endogenous tissue transglutaminase. Eur J Immunol 31, 1317-1323.

19. Szymczak LC, Kuo HY \& Mrksich M (2018). Peptide arrays: development and application. Anal Chem 90, 266-282.

20. Hall NJ, Rubin G \& Charnock A (2009) Systematic review: adherence to a gluten-free diet in adult patients with coeliac disease. Aliment Pharmacol Ther 30, 315-330.

21. Norsa L, Tomba C, Agostoni C, et al. (2015) Gluten-free diet or alternative therapy: a survey on what parents of celiac children want. Int J Food Sci Nutr 66, 590-594.

22. Kelly CD, Murray JA, Leffler DA et al. (2019) CNP-101 prevents gluten challenge induced immune activation in adults with celiac disease. United Eur J 7, 85.

23. Branchi F, Tomba C, Ferretti F, et al. (2009) Celiac disease and drug-based therapies: inquiry into patients demands. Digestion 93, 160-166.

24. Frisoni M, Corazza GR, Lafiandra D, et al. (1995) Wheat deficient in gliadins: promising tool for treatment of coeliac disease. Gut 36, 375-378. 